\title{
Prolactin and thyrotrophin response to thyrotrophin-releasing hormone in growth hormone deficiency
}

\author{
H FRISCH, K HERKNER, E SCHOBER, W STÖGMANN, F WALDHAUSER, AND M WEISSEL \\ Department of Paediatrics, II Medical Department, University of Vienna School of Medicine, Ludwig Boltzmann \\ Institut für klinische Endokrinologie und Nuklearmedizin; G. v. Preyer'sches Kinderspital, Vienna, Austria
}

SUMMARY Basal and thyroid-releasing hormone-stimulated $\left(200 \mu \mathrm{g} / \mathrm{m}^{2}\right)$ prolactin and thyroidstimulating hormone (TSH) levels were measured in 31 patients with hypopituitarism (13 isolated growth-hormone deficiencies and 18 multiple pituitary hormone deficiencies). The results were compared with the prolactin response in 76 healthy prepubertal children. Normal prolactin concentrations were found in 13 patients whereas 11 had increased levels. TSH levels were either normal or increased in patients who were considered to have hypothalamic disorders. Decreased prolactin response was present in 7 children, 6 of whom had multiple pituitary deficiencies. Their TSH response was decreased as well, indicating pituitary failure. There was good overall correlation of peak prolactin with peak TSH concentrations. Some patients with 'isolated' growth hormone deficiency had an abnormal prolactin response indicating an additional hormonal deficiency. All patients with low levels of serum thyroxine had abnormal prolactin or TSH levels, high in some, low in others. Two euthyroid patients with increased prolactin stimulation became hypothyroid during treatment with growth hormones, thus questioning whether prolactin is a more sensitive indicator of early thyroid insufficiency than thyroxine or TSH levels.

The administration of TRH has been shown to stimulate TSH secretion as well as that of PRL from the anterior pituitary. In addition, PRL is under the control of an inhibitory hypothalamic factor which is brought to the anterior pituitary lactotrophs by the portal blood system. Disorders of the hypothalamus or the pituitary stalk (infiltrations, inflammations, mass lesions) may therefore result in increased PRL concentrations. ${ }^{1}$ However, in patients with complete pituitary destruction, as in Sheehan's syndrome, lack of PRL stimulation is found. ${ }^{2}$ These different response patterns may be useful in differentiating between hypothalamic and pituitary localisation of the primary defect in hypopituitarism. We have therefore studied the basal and TRH-stimulated TSH and PRL levels in children with idiopathic and organic hypopituitarism and compared the different response patterns with results in 76 normal children.

\section{Patients and methods}

Thirty-one patients with hypopituitarism were studied (Table 1); 13 had idiopathic IGD and 18 had MPD. Four of the MPD patients had brain tumours and were studied postoperatively. Two children had septo-optic dysplasia, one of whom (Case 18) died at age $2 \frac{1}{2}$ years. At necropsy the pituitary gland was found to be very small, the optic nerve and tract and the optic chiasma had severe malformations, but no macroscopic changes of the hypothalamus could be seen.

One patient (Case 25) was studied during T4 replacement therapy. The remaining hypothyroid

\begin{tabular}{|ll|}
\hline PRL & $=$ prolactin \\
TSH & $=$ thyroid stimulating hormone \\
TRH & $=$ thyroid releasing hormone \\
IGD & $=$ isolated growth hormone \\
& deficiency \\
MPD & $=$ multiple pituitary hormone \\
& deficiencies \\
GH & $=$ growth hormone \\
T4 & $=$ thyroxine \\
LH-RH & $=$ luteinising hormone-releasing \\
ACTH & hormone \\
11-OHCS & $=11$-hydroxycotrophic hormone \\
\hline
\end{tabular}


Table 1 Chronological age and bone age, pubertal stage, and pituitary hormone deficiencies (in addition to GH deficiency) in patients with IGD (Cases 1-13), organic hypopituitarism (Cases 14-17), and MPD (Cases 18-31)

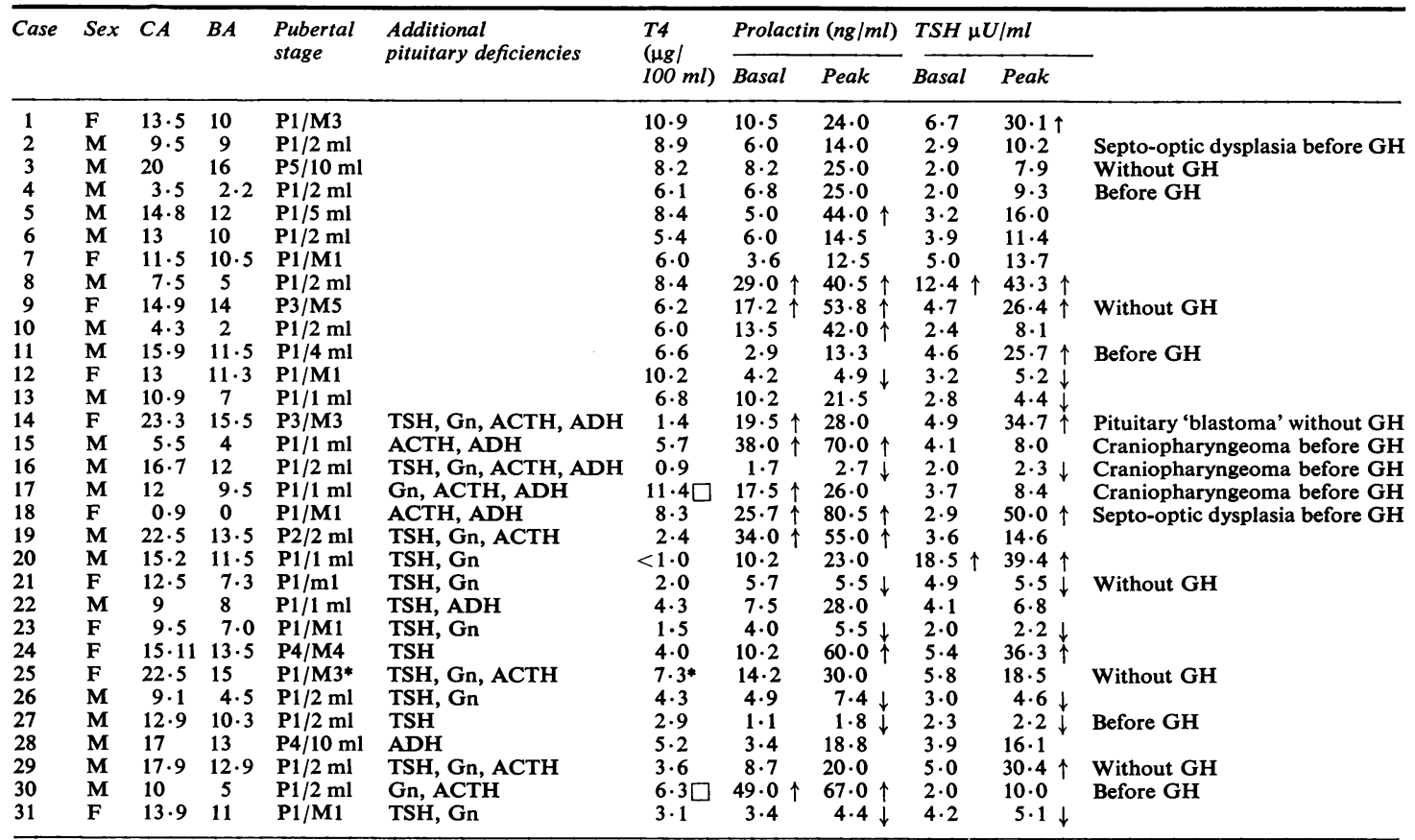

Serum T4, basal and peak PRL and TSH levels, were evaluated as increased ( $\uparrow$ ) or decreased ( $\downarrow$ ) (see text). Treatment with T4 at the time of testing $\left(^{*}\right)$; euthyroid patients who became hypothyroid during GH treatment $(\square)$. GH therapy had not been initiated (before GH), or it had been finished or interrupted (without $\mathrm{GH}$ ) at the time of testing; the other patients were on $\mathrm{GH}$.

$\mathbf{C A}=$ chronological age, $\mathbf{B A}=$ bone age.

Conversion: traditional to $S I$ units-T4 $1 \mu \mathrm{g} / 100 \mathrm{ml} \approx 12.87 \mathrm{nmol} / 1$.

patients (low serum T4) who were being treated with T4, together with 3 IGD patients who had been put on T4 tentatively because of poor growth velocity, stopped treatment about 5 weeks before testing.

Two patients (Cases 17 and 30) were tested before treatment with GH had been started and each had normal levels of T4; however, they became hypothyroid after $\mathrm{GH}$ treatment and their serum T4 levels became 4 and $3.6 \mu \mathrm{g} / 100 \mathrm{ml}$.

GH therapy was not started at the time of testing in 9 patients. In 6 treatment had either been completed or was interrupted for at least 4 weeks. In the other patients the last dose of $\mathrm{GH}$ was given 2 or 3 days before examination.

GH deficiency was confirmed by two of the following provocative tests: insulin tolerance, arginine infusion, intramuscular glucagon, or Ldopa/propranolol. TSH reserve was evaluated by estimating the serum T4, and the TRH test and gonadotrophin reserve by the LH-RH-test. ${ }^{3}$ ACTH secretion was evaluated by estimation of the serum 11-OHCS after insulin-hypoglycaemia, or by diurnal
11-OHCS rhythm. ${ }^{4}$ Antidiuretic hormone reserve was tested by free water clearance and the pitressin test. ${ }^{5}$

Chronological age and bone age of the patients, estimated by the method of Greulich and Pyle, ${ }^{6}$ and by Tanner puberty ratings, ${ }^{7}$ are shown in Table 1 .

For comparison, basal and stimulated PRL levels were determined in 76 healthy prepubertal children, 49 boys and 27 girls with a mean age of $9 \cdot 6 \pm 0 \cdot 36$ $(\overline{\mathrm{x}} \pm \mathrm{SE}$ ) (range 3 to 13 ) years. TSH normal levels were determined in 20 healthy children aged $7.9 \pm 0.49$ (SE) (range 4-10) years. The TRH tests were performed in the morning on resting and fasting patients by injecting $200 \mu \mathrm{g} / \mathrm{m}^{2} \mathrm{TSH}$ intravenously (TRH; Hoechst). Blood samples for TSH and PRL estimations were taken before and at 30,60 , and 90 minutes after TRH administration. Serum was separated and stored at $-20^{\circ} \mathrm{C}$. Levels of TSH and PRL were determined by radioimmunoassay using commercial kits (Beckman and Serono, respectively). WHO standard 68/38 was used for TSH and 75/504 for PRL. The inter- and intra-assay variance was less than $10 \%$ for both hormones. T4 was determined 
by radioimmunoassay (Byk Mallinckrodt), the normal range being $4.6-13.0 \mu \mathrm{g} / 100 \mathrm{ml}$. PRL and TSH results were interpreted as increased or decreased if they were outside the 2 SD range of the normal children.

\section{Results}

Normal children. In 76 normal children the mean basal PRL concentration was $7 \cdot 4 \pm 0 \cdot 38$ (range $2 \cdot 3$ to 17.5$) \mathrm{ng} / \mathrm{ml}$; the mean maximum level after TRH stimulation was $22.3 \pm 0.59$ (mean \pm SE) (range 13 to 35$) \mathrm{ng} / \mathrm{ml}$ (Table 2). There was no difference between genders in the PRL levels at any time of the test, so results for boys and girls were combined. The peak level was reached 30 minutes after TRH application in all probands except one (60 $\mathrm{min})$. The 60 - and 90 -minute mean concentrations were $14.3 \pm 0.44$ and $10 \cdot 3 \pm 0.46 \mathrm{ng} / \mathrm{ml}$, respectively. The basal level was not reached until 90 minutes after TRH.

The basal TSH concentration in healthy children was $4 \cdot 3 \pm 0 \cdot 25 \mu \mathrm{U} / \mathrm{ml}$, the peak after TRH stimulation was $13.9 \pm 0.91 \mu \mathrm{U} / \mathrm{ml}($ mean $\pm \mathrm{SE})$ and was reached after 30 minutes.

\section{Patients.}

\section{Normal PRL concentrations}

In 13 of 31 patients with hypopituitarism the mean basal and peak PRL levels $(7.5 \pm 0.91$ and $20 \cdot 7 \pm 1 \cdot 61 \mathrm{ng} / \mathrm{ml}$, respectively) were the same as in the normal group. Eight patients had IGD and 5 MPD. In 8 of these 13 normal PRL reactions the basal and stimulated TSH levels were normal as well. In 4 children the TSH response was increased, and in one (Case 13) the TSH remained low after stimulation. However, this child had IGD and had been treated with T4 up to 4 weeks before testing.

\section{Increased basal and stimulated PRL}

Increased PRL levels were found in 6 cases; in addition, on 3 occasions the maximum concentration was raised and twice a slight increase in the basal level was found. Five of these 11 cases had increased TSH stimulation as well, but in the remaining 6 the TSH response was normal. The mean basal PRL

Table 2 Basal and TRH-stimulated PRL levels in 76 healthy children, 49 boys and 27 girls, mean $\pm S E$

\begin{tabular}{lccc}
\hline Time (minutes) & Total $(n=76)$ & Boys $(n=49)$ & \multicolumn{1}{c}{ Girls $(n=27)$} \\
\hline 0 & $7.4 \pm 0.38$ & $7.5 \pm 0.49$ & $7 \cdot 7 \pm 0.69$ \\
30 & $22 \cdot 3 \pm 0.59$ & $22.2 \pm 0.80$ & $23.2 \pm 0.99$ \\
60 & $14 \cdot 3 \pm 0.44$ & $14.5 \pm 0.57$ & $13.6 \pm 0.66$ \\
90 & $10.3 \pm 0.46$ & $10.2 \pm 0.55$ & $10.8 \pm 0.81$ \\
\hline
\end{tabular}

level of these patients was $28 \cdot 7 \pm 3 \cdot 38 \mathrm{ng} / \mathrm{ml}$, and the peak was $56.9 \pm 4.58 \mathrm{ng} / \mathrm{ml}$. These values are significantly increased $(P<0.001)$. Four patients with increased PRL had IGD and 7 had MPD.

\section{Insufficient stimulation of $P R L$}

Insufficient stimulation of PRL was found in one IGD and six MPD patients. The IGD child had normal serum T4 levels and the TSH response was normal on one occasion but was found to be decreased when the test was repeated. Both tests were performed during GH therapy. All MPD patients as well as being hypothyroid had no TSH response, indicating pituitary failure. The mean basal PRL was $3.5 \pm 0.63 \mathrm{ng} / \mathrm{ml}$ and the peak level reached was $4 \cdot 6 \pm 0 \cdot 81(\bar{x} \pm S E)$. Both levels were significantly decreased when compared with the normal group $(\mathbf{P}<0.001)$.

As in the normal group, the peak levels of PRL were found 30 minutes after the TRH application in all patients. The significant correlation of peak TSH to peak PRL levels after TRH stimulation is shown in the Figure $(\mathrm{r}=0.48 ; \mathrm{P}<0.01)$.

\section{T4 concentrations}

All patients in the IGD group had normal T4 levels. In the MPD group 5 children had no thyroid insufficiency (Cases 15, 17, 18, 28, and 30) as shown by normal T4 levels, but in 4 of them PRL concentrations were increased and on one occasion TSH was increased as well. One patient (Case 25) remained on T4 during the test period and 2 children (Cases 17 and 30), who were tested before treatment

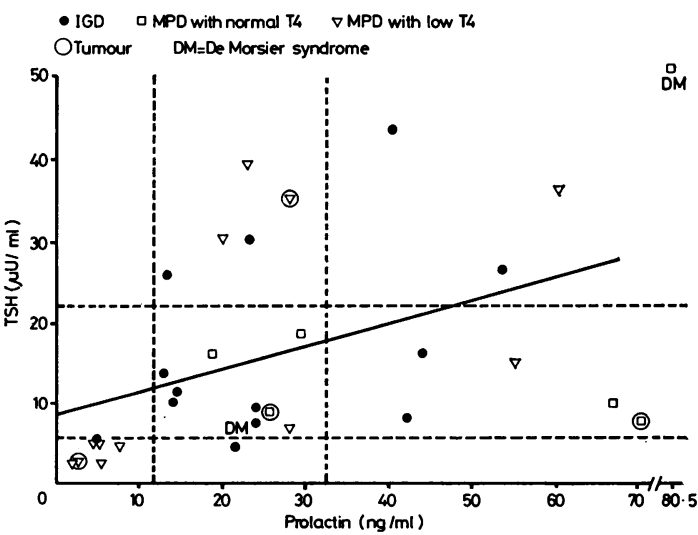

Figure Correlation of peak PRL with peak TSH concentrations after TRH application in 31 children with hypopituitarism. Dotted lines indicate the normal range $($ mean $\pm 2 S D)$ for the respective peak levels $(y=7.94+$ $0 \cdot 3 x)$. 
with GH, were still euthyroid but became hypothyroid when GH was started. Very low T4 levels were found in most of the MPD patients who had no PRL or TSH response after TRH.

\section{TSH results}

Normal basal and stimulated TSH was found in 7 of 13 IGD children and in 7 of 18 MPD patients. The corresponding PRL responses were either normal or increased. Two MPD children had decreased T4 levels, but in the remaining 12 patients $\mathrm{T} 4$ was normal $(7.08 \pm 0.53 \mu \mathrm{g} / 100 \mathrm{ml} ; \overline{\mathrm{x}} \pm \mathrm{SE})$.

\section{Increased TSH stimulation}

This was found in 9 patients; 2 had increased basal TSH. In 6 of these children the peak level was reached at least 60 minutes after TRH application. Primary thyroid disorder was excluded in these patients. Five such children also had high PRL levels.

\section{Decreased TSH response}

This was seen in 8 children; 6 had MPD, all of whom had decreased T4 levels $(2.45 \pm 0.5 \mu \mathrm{g} / 100 \mathrm{ml}$; $\overline{\mathbf{x}} \pm \mathbf{S E})$ as well as an inadequate PRL response.

\section{Discussion}

GH stimulation tests are not able to differentiate between hypothalamic and pituitary origin of the underlying disturbance in children with $\mathrm{GH}$ deficiency. The stimulation with hypothalamic releasing hormones which act directly on the pituitary gland, may give further information on this aspect. $^{8-12}$ TRH stimulates TSH as well as PRL release, albeit the latter is predominantly under an inhibitory hypothalamic control. ${ }^{13}$

Three different response patterns to TRH provocation were observed. Increased TSH or PRL concentrations, or both, were found in 15 of our patients, in 6 IGD cases with normal serum T4 levels and in 9 MPD patients; 5 of the latter group were hypothyroid. The fact that these patients were able to respond to TRH indicates that the pituitary gland is mainly intact but the hypothalamic TRH supply is inadequate for maintaining normal T4 concentrations. Increased TSH (and PRL) levels in combination with normal T4 levels may be interpreted as slight hypothalamic deficiency which as yet does not cause hypothyroidism. The increased and delayed TSH response is a typical reaction in patients with hypothalamic disorders, ${ }^{14} 15$ the increased PRL levels support the assumption of a hypothalamic lesion by a deficiency of inhibitory hypothalamic factor. ${ }^{1617}$ In addition, the fact that some of the children with increased PRL had normal T4 levels indicates that PRL is not totally dependent on T4 feedback.

Six of the MPD patients with increased TSH or PRL stimulation had an inadequate gonadotrophin response in the LH-RH test. It is well known that the gonadotrophin-producing cells require prolonged and repeated stimulation in order to recover their function after inadequate $\mathrm{LH}-\mathrm{RH}$ secretion ${ }^{18}$ and a single LH-RH test may not indicate gonadotrophin deficiency.

Two patients (Cases 17 and 30), who were tested before starting treatment with $\mathrm{GH}$, had normal serum T4 and normal TSH levels but increased PRL concentrations. Both patients became hypothyroid after starting GH therapy; this is a well-known observation but one that cannot be adequately explained..$^{19}$ Since T4 therapy is able to decrease high basal and stimulated PRL levels, ${ }^{9}{ }^{12}$ a feedback mechanism between these hormones can be assumed. The increased PRL levels in the 2 patients who became hypothyroid later may be a more sensitive indicator of early thyroid insufficiency than T4 or TSH. This observation has to be confirmed by further studies and might allow an earlier start of thyroxine substitution.

A decreased TSH and PRL stimulation was found in 8 patients, 6 of whom had multiple deficiencies and very low serum T4 concentrations. In these patients a defect in the pituitary gland is postulated with a failure of pituitary hormone synthesis or release. It is remarkable that none of our patients had solely PRL deficiency in addition to GH deficiency.

The finding of TSH and PRL unresponsiveness in patients with 'isolated' GH deficiency raises the question of proper classification. However, it is difficult to understand why such patients are euthyroid. Obviously small amounts of TSH are sufficient to maintain a euthyroid condition.

The patients with normal TSH and PRL response had normal T4 levels, with the exception of one patient (Case 22) in whom it was slightly decreased. These children are better classified as having a hypothalamic disorder. The child who was tested during T4 therapy (Case 25) cannot be classified. The patients with tumours demonstrated heterogeneous patterns of hormone response which might have been due to different surgical techniques and postoperative procedures. However, one child (Case 15) had a craniopharyngioma recurrence after the finding of an increased PRL level and this was thought to be a useful indicator. ${ }^{21}$ It was shown recently that PRL might play a role as stimulator of somatomedin and thus maintain normal growth in patients with pituitary tumours and GH deficiency. ${ }^{22}$ Two of our GH-deficient craniopharyngioma 
patients (Cases 15 and 16) had continued to grow normally without GH therapy; one had an increased PRL concentration but in the other it was decreased. Two patients with septo-optic dysplasia were included in the study. One of them demonstrated a hormonal response pattern which indicated hypothalamic involvement, with the highest stimulated PRL level observed in this series. A general correlation of peak PRL with peak TSH concentrations was demonstrated. However, divergent reactions of TSH and PRL to TRH may be explained in part by the different sensitivity of lactotrophic and thyrotrophic cells to TRH-stimulation or T4 feedback inhibition. ${ }^{8} 23$

In this cross-sectional study there was no indication that prolonged GH therapy influenced PRL secretion. ${ }^{1012} 24$

In conclusion, we found if a patient with isolated GH deficiency showed an abnormal PRL release, either high or low, it indicated an additional hormonal deficiency. Increased PRL release was shown to occur in euthyroid as well as in hypothyroid patients, raising the question of PRL dependency on T4 feedback. However, some patients with increased PRL stimulation who were euthyroid, became hypothyroid during GH therapy. Increased PRL release may therefore be an indicator of early thyroid insufficiency.

We thank Miss E Stransky for technical assistance and Mrs G Jagob for help with the preparation of the manuscript.

\section{References}

1 Kleinberg D L, Noel G L, Frantz A G. Galactorrhea: a study of 235 cases, including 48 with pituitary tumors. $N$ Engl J Med 1977; 296: 589-600.

2 Schwinn G, Von Zur Mühlen A, Köbberling J, Halves E, Wenzel K W, Meinhold H. Plasma prolactin levels after TRH and chlorpromazine in normal subjects and patients with impaired pituitary function. Acta Endocrinol 1975; 79: 663-76.

3 Frisch H, Waldhauser F, Havelec L, et al. Gonadotropin responsiveness to luteinizing hormone-releasing hormone in prepubertal and pubertal children with growth hormone deficiency. Acta Paediatr Scand 1982; 71 : 579-87.

4 Pichler E. Zur indirekten Stimulation der Nebennierenrinde. Wien Med Wochenschr 1972; Supplement 6, 2-16.

5 Alsever R N, Gotlin R W. Handbook of endocrine tests in adults and children, second edition. Chicago: Year Book Medical Publishers, 1978.

- Greulich W W, Pyle S I. Radiographic atlas of the hand and the wrist. Stanford, California: Stanford University Press, 1959.

7 Tanner J M. Growth at adolescence, second edition. Oxford: Blackwell, 1962; 28-39.

8 Kaplan S L, Grumbach M M, Friesen H G, Costom B H. Thyrotropin releasing factor (TRF) effect on secretion of human pituitary prolactin and thyrotropin in children and in idiopathic hypopituitary dwarfism: further evidence for hypophysiotropic hormone deficiencies. $J$ Clin Endocrinol Metab 1972; 35: 825-30.

9 Foley T P, Jr, Jacobs L S, Hoffman W, Daughaday W H, Blizzard R M. Human prolactin and thyrotropin concentrations in the serums of normal and hypopituitary children before and after the administration of synthetic thyrotropin releasing hormone. J Clin Invest 1972; 51: 2143-50.

10 Okada Y, Onishi T, Tanaka K, et al. Prolactin and TSH responses to TRH, chlorpromazine, and L-Dopa in children with human growth hormone deficiency. Acta Endocrinol 1978; 88: 217-26.

11 Batrinos M L, Pavlou S N, Pitoulis S A, et al. Assessment of prolactin release in pituitary dwarfism with the sulpiride test. Clin Endocrinol 1978; 8: 197-205.

12 Roitman A, Assa S, Pertzelan A, Zadik Z, Laron Z. Prolactin secretion in 70 patients with growth hormone deficiency. Eur J Pediatr 1980; 133: 251-8.

13 Frantz A G. Prolactin. $N$ Engl J Med 1978; 298: 201-7.

14 Foley T P, Jr, Owings J, Hayford J T, Blizzard R M. Serum thyrotropin responses to synthetic thyrotropinreleasing hormone in normal children and hypopituitary patients. J Clin Invest 1972; 51 : 431-7.

15 Illig R, Krawczynska H, Torresani T, Prader A. Elevated plasma TSH and hypothyroidism in children with hypothalamic hypopituitarism. J Clin Endocrinol Metab $1975 ; 41$ : 722-8.

16 Nose O, Iida Y, Harada T, Okada S, Yabuuchi H, Miyai $\mathrm{K}$. Hypothalamic-pituitary functions in patients with idiopathic pituitary dwarfism. Eur J Pediatr 1978; 129: 1-9.

17 Suter S N, Kaplan S L, Aubert M L, Grumbach M M. Plasma prolactin and thyrotropin and the response to thyrotropin releasing factor in children with primary and hypothalamic hypothyroidism. J Clin Endocrinol Metab 1978; 47: 1015-20.

18 Yoshimoto $Y$, Moridera $K$, Imura $H$. Restoration of normal pituitary gonadotropin reserve by administration of luteinizing hormone-releasing hormone in patients with hypogonadotropic hypogonadism. $N$ Engl J Med 1975; 292: 242-5.

19 Lippe B M, Van Herle A J, La Franchi S H, Uller R P, Lavin N, Kaplan S A. Reversible hypothyroidism in growth hormone-deficient children treated with human growth hormone. J Clin Endocrinol Metab 1975; 40: 612-8.

20 Sato T, Suzuki Y, Taketani T, et al. Enhanced peripheral conversion of thyroxine to triiodothyronine during hGH therapy in GH deficient children. J Clin Endocrinol Metab 1977; 45: 324-9.

21 Rogol A, Eastman R C. Prolactin and pituitary tumors. Am J Med 1979; 66: 547-8.

22 Clemmons D R, Underwood L E, Ridgway E C, Kliman $B$, Van Wyk J J. Hyperprolactinemia is associated with increased immunoreactive somatomedin $C$ in hypopituitarism. $J$ Clin Endocrinol Metab 1981; 52: 731-5.

23 Refetoff S, Fang V S, Rapoport B, Friesen H G. Interrelationship in the regulation of TSH and prolactin secretion in man: effects of L-Dopa, TRH, and thyroid hormone in various combinations. J Clin Endocrinol Metab 1974; 38: 450-7.

24 Connors $M$ H. Alteration of stimulated TSH and prolactin response in children treated with growth hormone. Life Sci 1977; 21 : 1505-9.

Correspondence to Dr H Frisch, Univ. Kinderklinik, Währinger Gürtel 74-76, A-1090 Wien, Austria.

Received 25 January 1982 